\title{
Affinities, Generic Classification and Biogeography of the Australian and New Zealand Mudfishes (Salmoniformes: Galaxiidae)
}

\author{
R.M. MCDOWALL \\ National Institute of Water and Atmospheric Research, P.O. Box 8602, Christchurch, New Zealand \\ Bob@chch.niwa.cri.nz
}

\begin{abstract}
The Australian mudfish, Galaxias cleaveri, resembles the three New Zealand mudfishes (Neochanna spp.) in general external morphology. It is the least specialised of a transformation series that includes all four mudfishes, in which the body is elongated, eyes are small, anterior nostrils long, tubular and forward directed, dorsal and anal fins low and long, flanges on the caudal peduncle well developed, pectoral fins small, paddle-shaped, and high on sides behind head, and pelvic fins reduced or lost. Unique specialisations in the vomerine-ethmoid region of the cranium and in the form of the pectoral girdle support the view that these four species are a monophyletic group. The Australian species is therefore included in Neochanna. The presence of a marine larval and juvenile life stage in the Australian species (diadromy) probably explains the distribution of the genus, with New Zealand species together derived from the Australian one or their common ancestor by dispersal across the Tasman Sea in prevailing ocean currents. The biogeography of the Australian and New Zealand species is consistent with post-Oligocene geology, and in particular with events during and since the Pleistocene.
\end{abstract}

MCDOWALL, R.M., 1997. Affinities, generic classification and biogeography of the Australian and New Zealand mudfishes (Salmoniformes: Galaxiidae). Records of the Australian Museum 49(2): 121-137.

The genus Neochanna was established by Günther (1867) to contain a small, cigar-shaped fish found when drains were being dug in swamplands on the West Coast of the South Island of New Zealand; it was described as $N$. apoda (Fig. 1D). While apparently a galaxiid (Galaxiidae) from its posterior dorsal fin and lack of scales, it was distinguished from Galaxias species by lacking pelvic fins, having flattened incisorlike jaw teeth, no endopterygoid teeth, long-based and low dorsal and anal fins that are nearly confluent with a distinctly rounded caudal fin, elongated, tubular anterior nostrils that point forwards, and small eyes (McDowall, 1970). Known commonly as "brown mudfish", it became well-known as a fish often found, semi-torpid and aestivating, in damp locations from which water had dried up-beneath logs and stumps, down old root holes around the bases of forest trees, and in similar, damp places where water is ephemeral 